\title{
Safety Supervision on Problems of Quality in Aviation Maintenance
}

B.Y. Li

Forth Department, First Aeronautic Institute of Air Force, china.

W. Niu

Department of Foundation, First Aeronautic Institute of Air Force, china

Y. Liu

Forth Department, First Aeronautic Institute of Air Force, china.

ABSTRACT: This paper studied the construction of aviation engineering quality safety supervision and management system and perfect, the characteristics of the aviation maintenance quality safety supervision work was summarized in this paper, the status quo of safety supervision and the problems were enumerated, put forward to accelerate the construction of standard of safety supervision system of locomotive depot aviation system, foster good cultural atmosphere of safety supervision the exploration of safety supervision, the development of scientific analysis system, establish supervisory cycle tracking system policy suggestions.

KEYWORD: Aviation maintenance; Quality; Safety supervision; Problem

\section{GENERAL INSTRUCTIONS}

The quality and safety supervision is the innovative measures in the construction process of modern aviation maintenance, is an important link to ensure the safety of aviation equipment play effectiveness, is an important part of the management of aviation maintenance quality and safety, to improve the quality of aviation equipment maintenance, to ensure the maintenance staff to comply with safety regulations, has very important significance to enhance aviation locomotive integrated security level.

\section{THE AVIATION MAINTENANCE QUALITY GUARANTEE SYSTEM SAFETY SUPERVISION CHARACTERISTICS}

Safety means no harm, do not cause a loss, no accident, the normal operation of the smooth progress of the development of things, the state of the people. The quality and safety supervision of aviation maintenance is to eliminate unsafe factors must through certain means, to achieve or enhance this state. That is, to maintain the seriousness of aviation maintenance regulations, supervise and urge the aviation maintenance personnel strengthen safety awareness, comply with the safety regulations, fulfill the security rules, so as to control the repair guarantee risk. Therefore, the aviation maintenance safety quality supervision, which belongs to the category of Management Science in general, but also has the particularity of the aviation maintenance itself, has the following characteristics:

\subsection{System}

Aviation safety maintenance quality supervision is a complex integrated management system. From the vertical perspective, system including top-down organs at all levels, including for first-line safety supervision office. Authorities pay attention to work safety supervision and management of the macro level, i.e. on the specific work of the organization, rules and regulations or the Trial Measures for specification [1]; safety supervision oriented line of Safety Supervision Office focuses on micro level, which is related to the safety and maintenance quality work all behavior supervision. Although the two are different, in safety supervision work level focusing on different, but closely around working locomotive quality aviation safety this goal. From transverse look, quality and safety supervision of aviation maintenance including aviation maintenance supervision, aviation maintenance inspection, all kinds of information collection and treatment and supervision, professional and technical research and management and implementation of all kinds of technical supervision plan, each link of supervision should conduct independent, there is a need for tight fit. At the same time, safety supervision work is also influenced by many external factors, such as fault investigation, technical bulletin effect of sudden 
execution, within the system of rules changes and other factors. Therefore, the quality and safety supervision and management is a system's engineering.

\subsection{Full}

Monitoring the aviation maintenance quality and safety is the effective supervision, specific personnel to perform the duties of the behavior on the one hand, shoulder the supervisory responsibilities of staff in accordance with the provisions of the procedures, methods and requirements, to monitor all related to safety and maintenance quality behavior, promote its operate according to the regulations to avoid mistakes. On the other hand, as part of the aviation maintenance work of all kinds of personnel, is itself also need to monitor the behavior of others to meet the requirements, therefore, the work of aviation maintenance quality and safety has a broad participation in.

\subsection{Timeliness}

The quality and safety supervision of aviation maintenance is based on real-time data security line security as the basis, but also to have information on the occurrence of system analysis. One is the safety supervision of aviation maintenance work is not only the quality of this kind of real-time information processing of a tracking, is a real-time comprehensive evaluation, through the evaluation of affairs, discover the hidden safety trouble and excluded in a timely manner, to achieve a comprehensive assessment to prevent human error, eliminating unsafe factors, the two is the processing of outdated information, if there is no safety issues in violation of safety supervision, should draw lessons, to develop measures to be improved, therefore, the timeliness of the locomotive quality safety supervision to highlight the work, as far as possible, the timely processing.

\section{CURRENT STATUS OF THE AVIATION ENGINEERING QUALITY AND SAFETY SUPERVISION WORK}

Aviation engineering quality and safety supervision implementation time is short, experience is little, the awareness of its importance is not enough, there are many problems in the implementation process.

\subsection{The aviation maintenance personnel understanding existence deviation on the safety supervision}

From the authorities to the frontline aviation maintenance personnel, have a certain understanding of the importance of safety supervision, found the problem to a closed loop problem solving treatment has been preliminarily formed. But part of the aviation maintenance personnel to the safety supervision work of understanding is not comprehensive enough, and some also have a conflict with emotions on safety supervise on work, mistaken for the work of a negative and a deliberate "fault" behavior, the staff to take the initiative to report the work of errors increased, active spirit of excellence has been enhanced, these is the former cadres in the management of work required to achieve, this is conducive to good operation quality and safety supervision of aviation maintenance in a certain extent, but everyone involved in the mutual supervision thoughts have not yet become the conscious action.

\subsection{Safety supervisors and line management cadre responsibility definition there is a blind area}

Safety supervision work is actively looking for other errors in the work, and let people find their errors in the work, is always a very to be ashamed of, safety supervision staff will think that this is not conducive to the harmonious relationship between the line, first of all, safety supervision staff there begs the question of thought, safety supervision serious strength is insufficient. Frontline staff do not want to let people find fault of their own ideas have not been eliminated, safety inspectors do not want much truer, resulting in supervision and be supervisor of twophase watch position. Secondly, the safety inspector active supervision work is insufficient, active supervision how to work with line management work go deep into the combination is a blind spot. Safety inspectors use what method to monitor, let be supervisors to better the work plays an effective role, and not out of bounds, not instead of position management too, once again, must consider how to make the management of cadres into the overall examination system, make the staff realize the supervision work for everyone, everyone is equal before the good atmosphere of supervision.

\subsection{Safety supervision system and mechanism is not perfect enough}

Standardization system of aviation maintenance safety supervision has not yet formed safety supervision, the lack of technical data and strong supporting the overall operation, standardized supervision standards, lack of basis in the process of implementation, the actual work and safety supervision of the paste too tight, main show is in: all kinds of regulations is messy, has not formed the system requirements suitable for the management of safety supervision. Notwithstanding the provisions of a series of laws and regulations, safety supervision 
work, but most of the lack of regulations, safety inspectors have doubt, according to what what, is difficult to accurately define. Although all kinds of regulations is more, but targeted regulations is less. As the task system of special equipment continued to increase, in the renewal of equipment at the same time, some lack of pertinence management regulations corresponding maintenance, only applied to the relevant provisions of similar, resulting in safety supervision work of chaos. Three is the provisions of operability is poor. Revised regulations subject confusion, resulting in duplication, crossover and even contradictory malpractice technical content, not know what course to take users.

\section{PROPOSALS TO IMPROVE THE QUALITY AND SAFETY SUPERVISION OF AVIATION MAINTENANCE WORK}

Supervision of aviation maintenance quality security is a systematic engineering, we should optimize the function, the perfect system, improve the method, improving the means, and strive to build "the idea first, follow the rules, process optimization, safety supervision mode of quantitative evaluation".

\subsection{To strengthen the construction of standard quality safety supervision system}

One is to improve the safety supervision standardization consciousness. The starting line maintenance personnel must begin from high quality, high standards, optimization in a variety of factors occupy an important position in the aircraft maintenance, including regulations and standardization, supervision and regulations of standardization and information evaluation standard elements. The two is to formulate the development planning of quality and safety standard system of locomotive depot aviation, and gradually form a system of standardization system. The investigation and study to strengthen the relevant departments, formulate the standard development plan for different models of quality and safety supervision system of locomotive depot aviation truth, from different working content, working time is different, especially the special requirements of mission to monitor the implementation of dynamic management, review the evaluation carried on strict quality safety supervision standards and timely safety supervision, and gradually improve the quality standard system. The three is to improve the normal safety supervision standardization organization. To strengthen the guiding role of higher authorities, the whole operation safety supervision system is in the top-level design of good. As a result of different models, training in different ways, first security work of the difference, from the content to the way of supervision timing, assessment work can be the first pilot run to the comprehensive promotion, and gradually improve the top-down full-time quality safety supervision mechanism, and from the input of funds to support, complete personnel, equipment, guarantee the standardization work steadily.

\subsection{To actively cultivate good Russian security supervision culture concept}

One is to establish the idea of people. People oriented is the core of the scientific concept of development, the core is also the safety supervision, safety supervision is the theme of the people, against the demands of human nature, could not get a good effect. We should change the past that kind of problem occurs on the mean error of cognitive processing, in order to improve the staff to take the initiative to guard consciousness, eliminate staff ideological concerns, let the overseers and under supervision coexist in a good ideological and cultural environment. The two is to establish a system of philosophy. [2] safety supervision is a systematic project, breaking stick boundaries to achieve comprehensive control, the coordination of every department, the personnel of various kinds mobilized, the use of various means, to maximize the overall effectiveness of surveillance, to create a good atmosphere and supervision work of everyone involved in the peri, forward security gateway, so as to achieve the control and prevention of risk. Three is to establish the concept of innovation. Safety supervision is facing a series of new situations and new problems, we should adopt multiorientation development achievements of modern scientific analysis, concrete analysis of parameters for the establishment of this particular group, scientific forecast, effectively follow up prevention, the establishment of detailed individual supervision archives, the specific reasons for the whole surface of the comprehensive understanding of the security situation. In this dynamic locomotive system in aviation, multi variable, human factors and changeable open complex system, work out the safety assessment method to evaluate the uncertainty of human error factors, basic events more complex logical relationship.

\subsection{Establish and improve the long-term mechanism of safety supervision management}

In order to fine as the request, to help to regulate, to information management system for support, reflects the "normative decision action" supervisory thought, and constantly improve the long-term mechanism of safety supervision and management. One is the implementation of sophisticated management mode. Change the current extensive mode of safety supervision, guide and implement the safety 
supervision of centralized, evaluation, assessment, that is, not only the single fault and error analysis of the implementation of the person himself, and the organizers and managers into the closed loop model of unity, to achieve integration supervision and be monitoring. Two is the implementation of safety supervision standardization, make the maneuverability is strong, the measures for the implementation of standardized the content of supervision norms, extensive, overcome the lightweight heavy qualitative heavy power light regulations rule type supervision, heavy light infield outfield supervision tendency, make safety supervision work more standardized. Three is the establishment of security information management system. Often the safety supervision information collecting input information management system, to achieve safety supervision information resources sharing, through comprehensive analysis, put forward with pertinence measures.

\section{REFERENCES}

[1] Li, Q.F. 2014 .The civil aviation safety management system of civil aviation safety management on. Management observation. 7(6): 70.

[2] Yu, H.T. 2011.Civil aviation safety analysis and management of. Doctoral dissertation of Shanghai Univer. 5(4): 10. 